\title{
A dinâmica da área, do rendimento e dos preços sobre o valor da produção do feijão e da soja no Rio Grande do Sul e a dependência temporal entre esses componentes
}

\author{
The dynamics of the area, yield and price on the \\ value of production of beans and soy in Rio Grande do Sul and the \\ temporal dependence between these components
}

\author{
Dienice Ana Bini ${ }^{I}$ Mario Duarte Canever ${ }^{I I}$
}

\section{RESUMO}

Objetiva-se neste artigo avaliar o crescimento do valor da produção (VP) do feijão e da soja no Rio Grande do $\mathrm{Sul}(\mathrm{RS})$, baseado no comportamento de seus determinantes área, rendimento e preço. Também se pretende determinar como choques nestes componentes transmitem-se de uma safra para outra no VP. Utilizaram-se dados de área, rendimento e preço do feijão preto e da soja no RS de 1977 até 2010. A metodologia shift-share permitiu decompor a importância de cada item sobre a variação do valor da produção. O ferramental de séries temporais permitiu obter o efeito de um choque em uma variável, ceteris paribus, sobre as demais. No curto prazo, o rendimento é o principal responsável pela variação do VP. Entretanto, no longo prazo, a queda dos preços reais de ambos os produtos é o fator determinante na redução dos seus valores da produção. $O$ valor da produção reage positivamente a choques positivos na área, rendimento e preço no ano corrente ao choque. Em geral, os ajustes são mais dinâmicos na soja do que no feijão.

Palavras-chave: decomposição do valor da produção, soja, feijão, VAR, Rio Grande do Sul.

\section{ABSTRACT}

Black beans and soybeans are important agribusiness activities in the Rio Grande do Sul, but they present distinct features at the production and at the marketing levels. The aim of this article is to evaluate the production value (PV) growth of these activities through its decomposition into three main components: area, productivity and price. The study also aims to determine how shocks in these variables are transmitted from one agricultural season to another in the PV. The data used comprised the period of 1977 to 2010 and the shift share's model was used to decompose the share of each component on the VP growth. Additionally, it was used a series of vector auto regression models to determine the current and lagged effects of these components over PV. The results show that in the short run the component productivity is the main responsible for variation in the $P V$. However, in the long run the decrease in the real prices is the most important determinant of the PV reduction. Positive shocks on the three components yields immediately positive reaction on $P V$. The propagation of the effects resembles the cobweb model with more dynamics adjustments for soybean than for black beans.

Key words: shifts on production value, soybean, bean, VAR, Rio Grande do Sul.

\section{INTRODUÇÃO}

Arelevância do agronegócio no Rio Grande do Sul, é um fato conhecido e importante, sendo um dos principais responsáveis pela geração de riqueza e equilíbrio das contas estaduais ${ }^{\mathrm{a}}$. A soja e o feijão são culturas de destaque na atividade agrícola estadual, porém são produzidas em sistemas produtivos distintos, assim como comercialização e fins. A soja é destinada em grande parte para exportação, fabricação de rações e produção de biodiesel, enquanto que o feijão destina-se ao consumo humano no mercado interno.

Como produto de exportação, a soja possui preços altamente correlacionados com as cotações internacionais (CHRISTOFOLETTI \&DA SILVA, 2011), resultantes das condições comerciais internas e externas. Já o feijão como produto tipicamente destinado ao consumo interno, e, em parte, produzido pela agricultura de subsistência (ALVARES et al., 2011), apresenta desempenho mais modesto. Agravando o quadro, está o fato de o Rio Grande do Sul

\footnotetext{
'Departamento de Economia, Administração e Sociologia (LES), Escola Superior de Agronomia “Luiz de Queiroz” (ESALQ), 13418-900, Piracicaba, SP, Brasil. Email: dienicebini@gmail.com. Autor para correspondência.

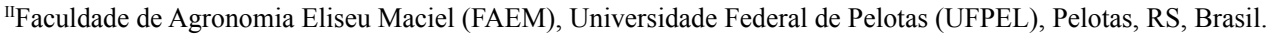
Recebido 02.06.14 Aprovado 30.09.14 Devolvido pelo autor 15.01.15 CR-2014-0846.R1
} 
produzirprincipalmente feijão preto, cujo preçoémuito suscetível à entrada de feijão oriundo da Argentina. Embora ambas as culturas sejam produzidas pela agricultura familiar, na produção de soja, predomina um sistema altamente tecnificado, com colheita e plantio mecanizado, uso de sementes melhoradas, adubação segundo recomendação e adequado manejo de pragas, doenças e plantas espontâneas; práticas que resultam na obtenção de altos rendimentos por unidade de área. De outro lado, o feijão é, em geral, produzido por pequenos produtores que utilizam menor nível tecnológico. Não há muitas variedades melhoradas, as sementes utilizadas no plantio, frequentemente, são oriundas da propriedade, sendo comum a ocorrência de mistura varietal. A adubação, o manejo de pragas, doenças e plantas espontâneas nem sempre é realizada adequadamente, o que deprime os níveis de produtividade.

A soja e o feijão são culturas de interesse estratégico no Rio Grande do Sul; contudo, em função das diferenças produtivas e comerciais, que afetam ambas as atividades, há expectativas de que o volume econômico movimentado por estas atividades não seguem uma trajetória única. Além disso, sabese que o valor da produção de ambas as atividades é declinante nas últimas décadas. Um dos fatores causadores deste fenômeno é a já conhecida tendência de queda dos preços reais das commodities agrícolas (SOUZA \& VIANA, 2007). Outro fator importante são as constantes frustrações de safra, provocadas, geralmente, por secas que causam variabilidade dos rendimentos e da produção agrícola no Estado (BERLATO \& CORDEIRO, 2005). Ademais, devido à escassez de terras ociosas, variações no valor econômico gerado são restringidas pela já esgotada área agrícola. A expansão de área de uma cultura só é possível pela alocação de terras utilizadas com outra(s) cultura(s), nas quais se privilegiam aquelas com maior e/ou mais segura expectativa de rentabilidade.

Com base nessas informações, espera-se que: (1) para a soja, a área cultivada apresente maior variação de um ano para outro, pois, a depender do preço da safra anterior, a área plantada pode variar, afetando o VP. Já o feijão tem uma parcela da produção realizada por pequenos agricultores, para alimentação das famílias, que independe do preço da safra anterior e assim as variações da área cultivada sejam menores; (2) para a soja, o componente rendimento seja mais relevante para as variações do valor da produção, por ser uma cultura que apresenta alta produtividade e, portanto, é mais sensível às condições climáticas e tratos culturas realizados em cada safra; (3) ao longo da série analisada, o comportamento do valor da produção de soja possa apresentar diferenças em relação ao feijão, devido à área cultivada com soja no RS ter aumentado, enquanto a área cultivada com feijão ter diminuído.

Assim, primeiramente, objetiva-se decompor o valor da produção da soja e do feijão, no $\mathrm{RS}$, em seus componentes área, rendimento e preço, para determinar qual dessas variáveis é mais relevante para o comportamento do VP; de posse desses resultados, objetiva-se avaliar se há diferenças entre essas culturas, dado que há perceptíveis diferenças nos sistemas produtivos e destino, conforme já apresentado anteriormente.Também objetivou-se identificar as relações de dependência temporal entre os três componentes e o VP.

A escolha da soja para objeto de análise está baseada no fato de ser o principal grão produzido no estado (IBGE, 2014). Já a escolha do feijão se justifica por ser utilizado como fonte de renda de grande parte de pequenos produtores, assim como utilizando quase que in natura como fonte proteica na alimentação da população brasileira. Como um dos objetivos é justamente verificar se há diferenças no VP entre uma cultura comercial e outra mais dedicada à subsistência, acredita-se que essas culturas são as mais adequadas.

\section{Hipóteses do estudo}

Os incrementos tecnológicos melhoram o rendimento da agropecuária, já a variabilidade climática atua de forma dual. Às vezes, o clima (principalmente em termos de precipitação) influencia positivamente, mas, em outras ocasiões, a estiagem afeta a produção, provocando redução da produtividade.Portanto, o componente rendimento é muito variável e acompanha as condições climáticas. Nesse sentido, FOCHEZATTO \& GHINIS (2009) e BERLATO \& CORDEIRO (2005) apontam que a instabilidade da precipitação pluvial é a principal causa da variabilidade dos rendimentos e da produção agrícola do Estado numa perspectiva interanual. Porém, numa perspectiva de longo prazo, a tendência de queda dos preços reais dos produtos agropecuários é esperada como o principal componente influenciador do desempenho econômico destas atividades. Ou seja, apesar do aumento dos rendimentos em ambas as atividades, estes não foram suficientes para compensaras perdas geradas pelas quedas de preços reais desses produtos, dado que o VPé declinante. Logo:

H1 - o efeito preço é o componente mais importante para a variação do valor econômico das atividades soja e feijão nas últimas décadas no Rio Grande do Sul, contudo devido às diferenças apresentadas anteriormente, espera-se que esse efeito seja menor no feijão no que na soja. 
O VP da agropecuária segue um padrão de comportamento que envolve defasagens no tempo. Os agricultores tomam suas decisões de produzir baseados em experiências passadas, isto é, os produtores são sensíveis às alterações de preços $\mathrm{e}$, tanto o rendimento quanto a área cultivada em um ano afeta a decisão de plantioseguinte, a tecnologia a ser usada, o nível de produtividade a ser atingido e consequentemente os preços a serem praticados (ERDAL et al., 2009). Esta dinâmica assemelha-se ao modelo "Teia de Aranha" . Portanto:

H2 - os valores da produção da soja e do feijão no Rio Grande do Sul dependem de variações defasadas nos componentes, área, rendimento e preço.

\section{MATERIAL E MÉTODOS}

Para a execução do presente trabalho, foram utilizados dados de preços pagos aos produtores no Rio Grande do Sul, disponibilizados pela EMATER-RS, para os períodos de 1977 a 2010. Estes preços foram convertidos para a moeda corrente e deflacionados pelo índice IGP-DI, com base em dezembro de 2010. Já os valores de área, rendimento e produção do feijão e da soja foram coletados na CONAB.

Como procedimentos analíticos utilizouse o Modelo Estrutural-Diferencial (Shift-Share) para decompor a taxa de crescimento do valor da produção do feijão e da soja nos componentes área, rendimento e preço. Isto é feito pela estimação da importância relativa de cada fator sobre os acréscimos ou decréscimos do valor da produção. $\mathrm{O}$ modelo descreve o crescimento do valor da produção entre um período base " 0 " e um período final " $t$ ", a fim de encontrar a diferença $(\mathrm{V} t-V 0)$ entre os fatores que seriam os responsáveis pela variação do valor da produção: área, rendimento e preço. Detalhes dessa metodologia podem ser encontrados em: ARAUJO \&CAMPOS (1998); CARVALHO et al. (2012); SOARES et al. (2013).

Para compreender como as variáveis independentes (área, rendimento e preço) e dependente (Valor da produção) se relacionam no tempo, utilizou-se o ferramental econométrico de séries temporaiscom a estimação de um Vetor Auto Regressivo -VAR. Foram realizados os testes de raiz unitária (Dickey-Fuller Aumentado e PhillipsPeron), que indicaram que as séries são estacionárias em primeira diferença. Os testes de cointegração de Johansen, baseado na estatística do traço e estatística do máximo auto valor, não identificaram a presença de vetores cointegrantes. Quanto às defasagens, com base nos testes Akaike, o critério de Schwarz, o critério de informação de Hannam-Quinn e o Final Prediction Error e a ausência de autocorrelação dos resíduos (teste Ljung-Box), optou-se pelo uso de apenas um lag. Ao final, a partir do VAR, obteve-se a função impulso resposta, que permite verificar como uma variável responde a choques não esperados nas demais variáveis, neste caso, como o VP responde a choques na área, rendimento e preço. Detalhes dessa metodologia podem ser encontrados em GUJARATI (2006), BUENO (2008), SCALCO et al. (2012).

\section{RESULTADOS E DISCUSSÃO}

Analisando os dados, observa-se que a área cultivada com feijão diminuiu 41,1\% ${ }^{\mathrm{c}}$ de 1977 a 2010, decréscimos correspondentes a 1,8\% ao ano, enquanto que a área com soja apresentou aumento total de $13,9 \%$ ou crescimentos anuais de $0,02 \%$ (Figura 1 ). Ao que tudo indica, os agricultores gaúchos têm optado pelo cultivo da soja, em detrimento do feijão, provavelmente pela maior rentabilidade e estabilidade do mercado. Vê-se também que o feijão apresentou taxas de crescimento da produtividade $(2,1 \%$ a.a) superiores ao da soja (1,5\% a.a). Tal fato, embora pareça paradoxal, reflete a transição deste cultivo de uma atividade fundamentalmente de subsistência para uma atividade mais organizada ao longo dos últimos anos. Isto mostra também que, diferentemente da soja, a tecnificação da cultura do feijão ocorreu mais tardiamente, conforme constatado por ARRIAL (2012 - Informe Verbal ${ }^{\mathrm{d}}$ ). O ritmo de crescimento da produção de soja no estado (igual a 1,53\% a.a) foi superior ao do feijão, resultado atribuído não só pelo efeito rendimento, mas pelo aumento da área cultivada.

Os preços reais de ambos os produtos foram decrescentes no período, ao nível de $70 \%$ para o feijão e de 63,6\% para a soja. Considerando as quedas anuais ocorridas de 1977 a 1994, os preços do feijão e da soja diminuíram a um ritmo de 3,9\% a.a. Já de 1995 até 2010 (pós plano real), os preços do feijão continuaram a cair à taxa média de $2,5 \%$ a.a, enquanto que os preços da soja aumentaram $0,5 \%$ a.a. Isso é compreensível, uma vez que cerca de $44 \%$ da soja nacional é exportada (FAO, 2014), permitindo aos agricultores se beneficiarem do aumento dos preços internacionais. $\mathrm{O}$ valor da produção de ambas as culturas é decrescente (Figura 1). Contudo, a taxa de decréscimo é menor para a soja $(1,78 \%$ a.a) do que para o feijão (3,62\% a.a). A volatilidade do VP, dado pelo desvio padrão das séries, é maior na soja $(50,74)$ do que no feijão $(43,20)$. Portanto, a perspectiva de que o VP da soja é mais instável do que o do feijão se confirma nos resultados. Conforme já discutido 


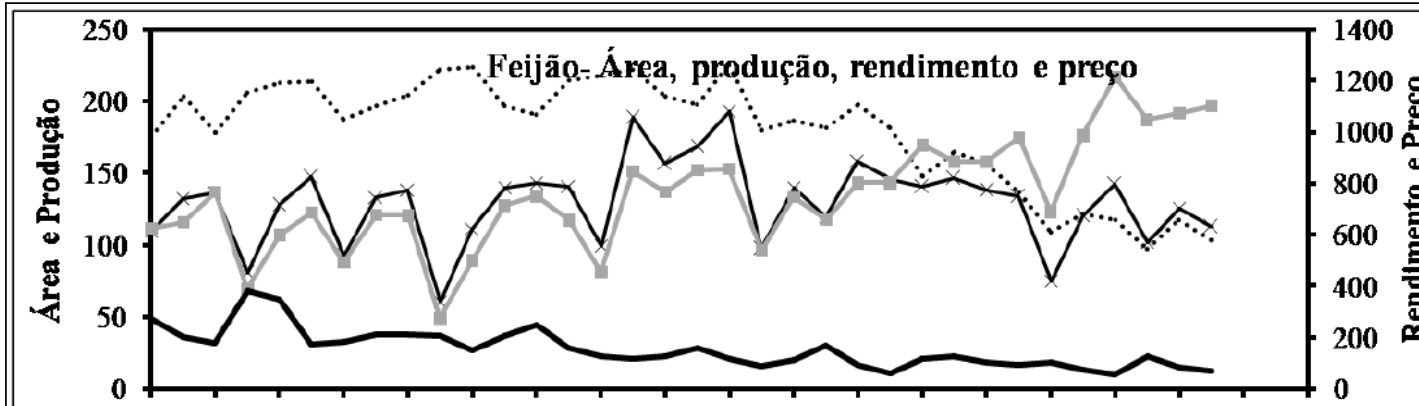

1977197919811983198519871989199119931995199719992001200320052007200920112013

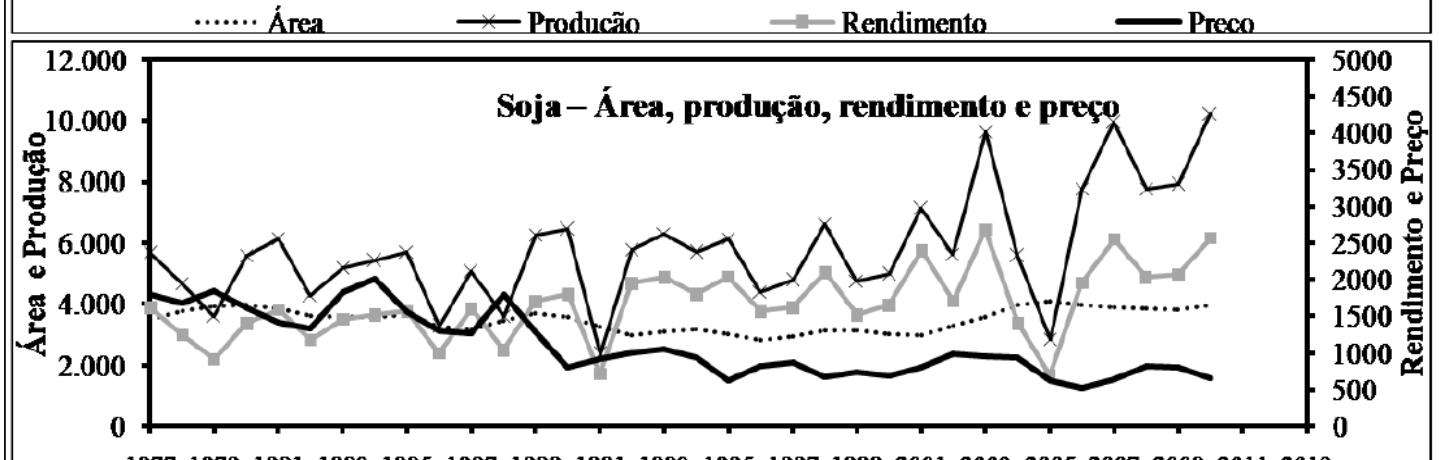

1977197919811983198519871989199119931995199719992001200320052007200920112013

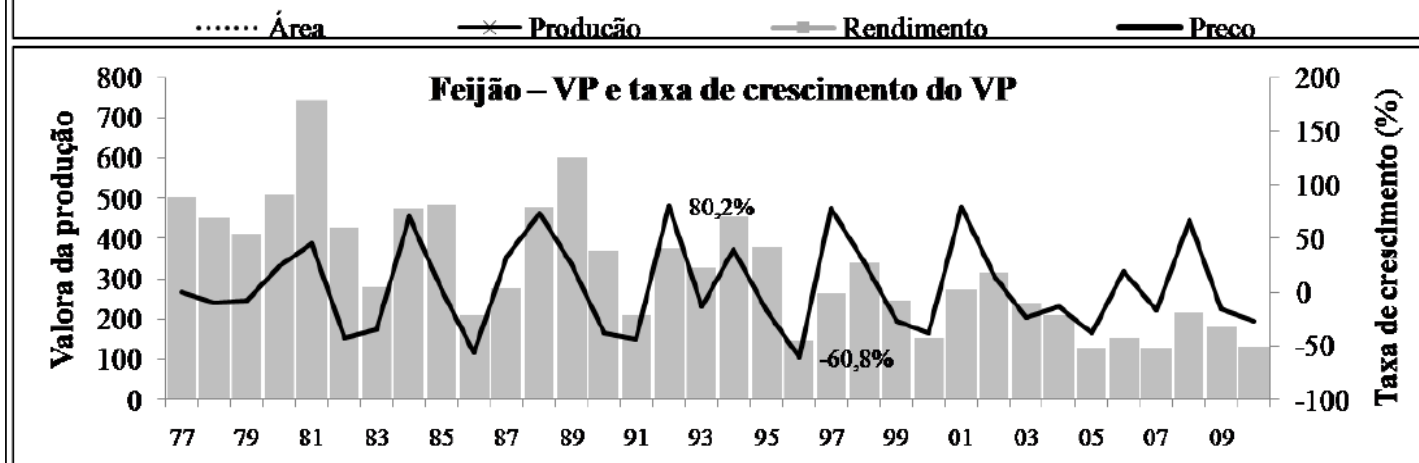

Valor da producão — Taxa de crescimento

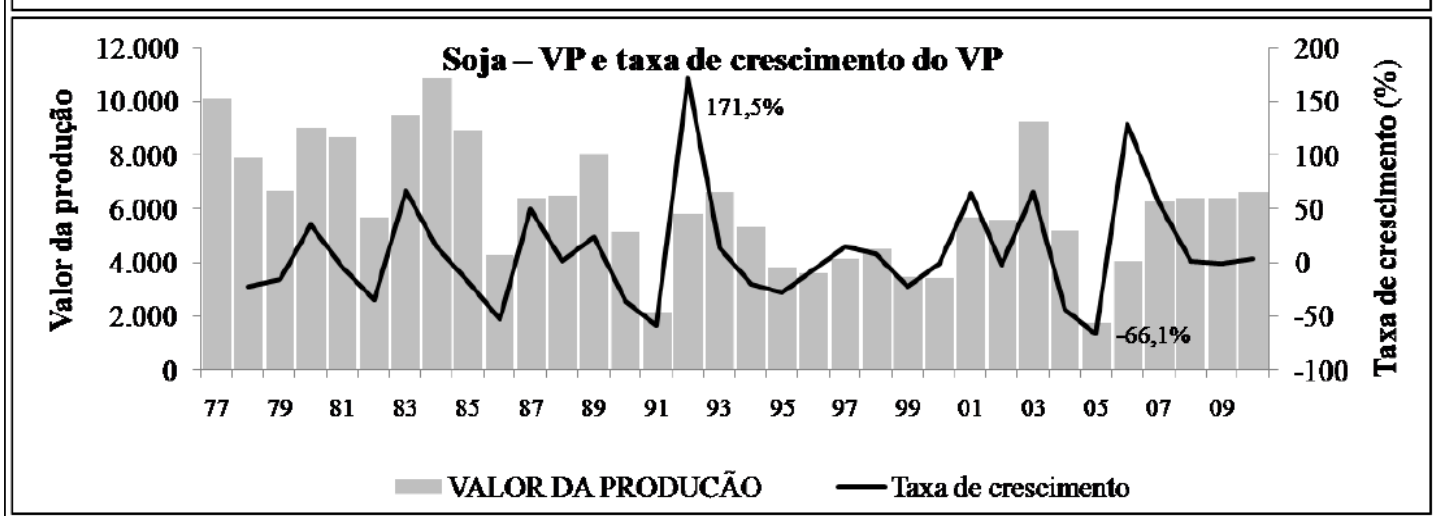

Figura 1 - Área (hectares), produção (milhões de $\mathrm{kg}$ ), rendimento $(\mathrm{kg} / \mathrm{ha})$, preço (R\$/saca), valor da produção (milhões de reais) e taxa de crescimento do valor da produção (\%) para feijão e soja no Rio Grande do Sul de 1977 a 2010. Fonte: Resultados da pesquisa.

Ciência Rural, v.45, n.6, jun, 2015. 
na seção introdutória, o feijão é uma cultura de subsistência, sendo uma parcela considerável da sua produção realizada por pequenos agricultores familiares, para a alimentação das famílias, independente dos preços. Soma-se a isso também o fato de a soja ser uma cultura mais tecnificada, com maior produtividade e, consequentemente, mais sensível a problemas climáticos, ou seja, em condições adversas, a redução de rendimento é maior na soja do que no feijão, o que provoca maior variação do VP.

A tabela 1 apresenta os resultados do modelo shift-share e discrimina a contribuição dos elementos área, rendimento e preço nas variaçõesdo valor da produção. Para o feijão, até o início do Plano Real, o rendimento era o fator que mais influenciava; já a partir deste período, o fator principal passou a ser o preço. Assim, na última década e meia, o fato

Tabela 1 -Valor da produção, taxa de crescimento do valor da produção e sua decomposição nos efeitos área, rendimento e preço do feijão e da soja no Rio Grande do Sul, 1997 a 2010.

\begin{tabular}{|c|c|c|c|c|c|c|c|c|c|c|}
\hline \multirow[t]{2}{*}{ Ano } & \multicolumn{2}{|c|}{---- Milhões de R\$ ---- } & \multicolumn{2}{|c|}{----- Variação (\%) ------ } & \multicolumn{2}{|c|}{---------- Área ----------- } & \multicolumn{2}{|c|}{------- Rendimento ------- } & \multicolumn{2}{|c|}{-------- Preço --------- } \\
\hline & Feijão & Soja & Feijão & Soja & Feijão & Soja & Feijão & Soja & Feijão & Soja \\
\hline 1977 & 500,96 & 10107,03 & - & - & - & - & - & - & - & - \\
\hline 1978 & 449,39 & 7881,25 & $-10,26$ & $-22,02$ & 16,4 & 7,56 & 4,47 & $-24,8$ & $-31,13$ & $-4,78$ \\
\hline 1979 & 412,24 & 6660,19 & $-8,28$ & $-15,49$ & $-12,47$ & 5,22 & 15,78 & $-28,23$ & $-11,59$ & 7,52 \\
\hline 1980 & 509,07 & 9022,41 & 23,58 & 35,47 & 15,28 & 0,94 & $-56,44$ & 54,11 & 64,74 & $-19,58$ \\
\hline 1981 & 741,9 & 8642,93 & 45,69 & $-4,21$ & 3,48 & $-3,46$ & 55,31 & 13,44 & $-13,11$ & $-14,19$ \\
\hline 1982 & 427,19 & 5672,32 & $-42,36$ & $-34,37$ & 0,45 & $-6,39$ & 14,73 & $-24,35$ & $-57,55$ & $-3,62$ \\
\hline 1983 & 280,3 & 9493,38 & $-34,45$ & 67,36 & $-12,28$ & -1 & $-24,86$ & 23,32 & 2,69 & 45,04 \\
\hline 1984 & 475,3 & 10892,86 & 69,71 & 14,74 & 4,93 & 0 & 39,16 & 3,91 & 25,61 & 10,83 \\
\hline 1985 & 484,15 & 8953,93 & 1,76 & $-17,8$ & 3,9 & 1,96 & $-0,15$ & 3,7 & $-1,98$ & $-23,46$ \\
\hline 1986 & 208,34 & 4263,54 & $-56,9$ & $-52,38$ & 8,51 & $-10,34$ & $-64,53$ & $-32,55$ & $-0,88$ & $-9,49$ \\
\hline 1987 & 276,16 & 6407,81 & 32,49 & 50,29 & 0,65 & $-3,1$ & 83,02 & 58,14 & $-51,19$ & $-4,75$ \\
\hline 1988 & 478,96 & 6486,21 & 73,16 & 1,22 & $-12,06$ & 10 & 37,29 & $-38,5$ & 47,93 & 29,72 \\
\hline 1989 & 602,23 & 8018,38 & 25,7 & 23,62 & $-2,77$ & 5,98 & 5,33 & 67,26 & 23,14 & $-49,62$ \\
\hline 1990 & 370,24 & 5148,48 & $-38,47$ & $-35,79$ & 12,27 & $-2,9$ & $-14,2$ & 5,71 & $-36,54$ & $-38,6$ \\
\hline 1991 & 208,53 & 2147,43 & $-43,69$ & $-58,29$ & 1,73 & $-8,6$ & $-31,02$ & $-54,84$ & $-14,4$ & 5,15 \\
\hline 1992 & 375,9 & 5831,55 & 80,17 & 171,56 & 1,86 & $-9,16$ & 87,57 & 155,19 & $-9,26$ & 25,53 \\
\hline 1993 & 326,92 & 6634,66 & $-13,01$ & 13,77 & $-8,35$ & 4,38 & $-8,75$ & 4,28 & 4,1 & 5,11 \\
\hline 1994 & 454,87 & 5304,74 & 39,21 & $-20,04$ & $-2,91$ & 2 & 10,63 & $-11,56$ & 31,49 & $-10,49$ \\
\hline 1995 & 377,56 & 3823,67 & $-17,03$ & $-27,92$ & 13,93 & $-4,65$ & 0,67 & 12,71 & $-31,63$ & $-35,98$ \\
\hline 1996 & 147,87 & 3593,12 & $-60,84$ & $-6,03$ & $-20,09$ & -7 & $-29,41$ & $-21,43$ & $-11,35$ & 22,4 \\
\hline 1997 & 263,7 & 4144,17 & 78,3 & 15,34 & 3,79 & 5 & 39,71 & 3,34 & 34,81 & 6,99 \\
\hline 1998 & 339,63 & 4494,68 & 28,88 & 8,46 & $-2,95$ & 7 & $-11,68$ & 31,7 & 43,5 & $-30,25$ \\
\hline 1999 & 247,24 & 3481,08 & $-27,23$ & $-22,55$ & 8,76 & $-0,5$ & 23,97 & $-27,48$ & $-59,96$ & 5,43 \\
\hline 2000 & 152,79 & 3441,85 & $-38,21$ & $-1,13$ & $-7,74$ & -4 & $-0,11$ & 8,21 & $-30,36$ & $-5,34$ \\
\hline 2001 & 273,35 & 5672,32 & 79,04 & 64,8 & $-18,6$ & $-1,3$ & 14,92 & 44,56 & 82,72 & 21,54 \\
\hline 2002 & 314,42 & 5581,18 & 14,98 & $-1,61$ & 11,33 & 11,3 & $-7,39$ & $-32,07$ & 11,04 & 19,16 \\
\hline 2003 & 239,46 & 9236,91 & $-23,81$ & 65,5 & $-5,36$ & 8,72 & $-0,21$ & 62,17 & $-18,23$ & $-5,38$ \\
\hline 2004 & 208,75 & 5198,27 & $-12,89$ & $-43,72$ & $-12,49$ & 10,5 & 9,4 & $-52,78$ & $-9,8$ & $-1,45$ \\
\hline 2005 & 129,12 & 1762,21 & $-38,16$ & $-66,1$ & $-20,43$ & 3 & $-23,49$ & $-51,65$ & 5,76 & $-17,45$ \\
\hline 2006 & 153,82 & 4039,1 & 19,19 & 129,21 & 12,06 & -3 & 48,23 & 175,38 & $-41,09$ & $-43,17$ \\
\hline 2007 & 128,67 & 6282,99 & $-16,36$ & 55,55 & $-3,79$ & $-1,9$ & 22,03 & 29,53 & $-34,6$ & 27,92 \\
\hline 2008 & 214,94 & 6403,07 & 67,14 & 1,91 & $-16,84$ & $-1,49$ & $-11,38$ & $-20,17$ & 95,36 & 23,57 \\
\hline 2009 & 180,8 & 6383,86 & $-15,91$ & $-0,3$ & 20,19 & $-0,3$ & 2,98 & 2,06 & $-39,09$ & $-2,06$ \\
\hline 2010 & 130,87 & 6646,68 & $-26,89$ & 4,12 & $-11,95$ & 4,02 & 2,38 & 25,13 & $-17,31$ & $-25,03$ \\
\hline $\begin{array}{l}\Sigma \text { em } \\
\text { Milhões } \\
\text { de Reais }\end{array}$ & $-368,70$ & $-3.460,29$ & - & - & 48,41 & $2.033,98$ & 296,22 & $2.704,93$ & $-713,33$ & $-8.199,21$ \\
\hline
\end{tabular}

Fonte: Resultados da pesquisa.

Ciência Rural, v.45, n.6, jun, 2015. 
preponderante no elo de produção do feijão foi a dependência do VP aos preços e não mais de forma tão intensa aos ganhos de rendimento.

A decomposição do crescimento do VP da soja é diversa da encontrada para o feijão. A variação do valor da produção em todo o período é dependente do efeito rendimento, e não do preço. Como o rendimento das lavouras é determinado, principalmente, pelas condições climáticas, afirmarse que a variação do VP é determinada fortemente pelas condições climáticas, ao invés dos preços do produto. Porém, no longo prazo (toda a série), a participação do efeito preço na evolução da movimentação econômica da soja é majoritária.

Portanto, no longo prazo, o preço é o que tem maior influência na movimentação econômica de ambas as atividades. Muito embora a economia gaúcha seja instável de um ano para outro (curto prazo), em função da variabilidade da produção agrícola resultar das condições climáticas que afetam os níveis produtivos, no longo prazo, as principais perdas em termos monetários ocorrem em função das quedas dos preços agrícolas. A hipótese 1 é aceita.

Nesse sentido, SOUZA \& VIANA (2007) constataram queda do preço real do feijão, soja, arroz, trigo e milho, no RS, para o período de 1973 a 2005. Os autores atribuíram tal resultado à expansão das áreas de lavouras e ao incremento de tecnologia no campo, resultando no aumento considerável da produção e produtividade das culturas.

Tendo o VP como variável dependente, é possível identificar como reage a um choque não antecipado em cada uma das demais variáveis. A figura 2 apresenta os resultados da função impulso-resposta, demonstrando que o VP aumenta imediatamente como resposta a choques em qualquer um dos três componentes, tanto para a soja como para o feijão. Já no segundo ano após o choque, os impactos tanto podem permanecer positivos quanto tornarem-se negativos, como aconteceu com o efeito do rendimento no valor da produção para ambas as culturas. Tal ajuste ocorreporqueaumentos de rendimento em uma determinada safra levam a quedas de preços na safra corrente e, por conseguinte, reduções de área plantada na safra seguinte. O resultado final deste mecanismo é a redução do volume econômico, movimentado pela atividade no ano seguinte.

$\mathrm{O}$ valor da produção da soja mostrou-se mais sensível a choques na área e no rendimento e os impactos se dissipam num prazo de cinco anos, enquanto que, no feijão, eles permanecem por período superior a dez anos. Depreende-se dos resultados que, para a atividade soja, os agricultores consideram o desempenho da atividade no ano anterior para planejar a produção, podendo optar por culturas substitutas, como o milho, por exemplo.

Os ajustamentos são mais rígidos no caso do feijão. A resposta defasada no valor da produção por mudanças nos três componentes é relativamente alta, mas os ajustes são lentos. Tal comportamento sugere que, no cultivo do feijão, as decisões ocorrem por força dos hábitos de produção e por se tratar de uma cultura de subsistência, sendo cultivada para a alimentação independente dos preços. Portanto, confirma-se a hipótese 2 de dependência temporal do valor da produção aos seus componentes, área, rendimento e preço, contudo.

Desses resultados, depreende-se que há diferenças entre uma cultura mais destinada à subsistência de outra mais destinada ao mercado. A área cultiva é mais instável para a soja e com maior dependência do preço da safra anterior, enquanto, para o feijão, a variação de área de uma safra para outra é menor e com menor dependência do preço da safra anterior. O efeito componente preço também tem comportamento diferenciado. Enquanto os preços da soja têm aumentado após o plano real, favorecido pela valorização da commodity no mercado internacional, o preço do feijão continua decrescendo.

\section{CONCLUSÃo}

Os resultados obtidos neste estudo permitem concluir que, embora a produção total de ambos os produtos tenham apresentado crescimento significativo desde final de 1970, as variações anuais de rendimento faz o valor da produção oscilar sobremaneira. Os rendimentos anuais são fortemente influenciados pelas condições climáticas e, no curto prazo, este fator é o principal determinantedo montante econômico movimentado no estado com a soja. Em relação ao feijão, se, no passado, o fator preponderante era também o componente rendimento, após o plano real, o componente preço responde pela maior parte da variação anual do valor da produção. A despeito de o componente preço ter influência no curto prazo, ou seja, na variação do valor da produção de um ano para outro, a principal contribuição deste componente é no longo prazo, pela sua característica de persistente declínio.

O efeito líquido dos componentes área e rendimento são positivos e compensam parte do impacto negativo do componente preço. A implicação óbvia destes resultados é que ambas as atividades, para serem sustentáveis no longo prazo, necessitam produzir a custos compatíveis aos preços de mercado. 


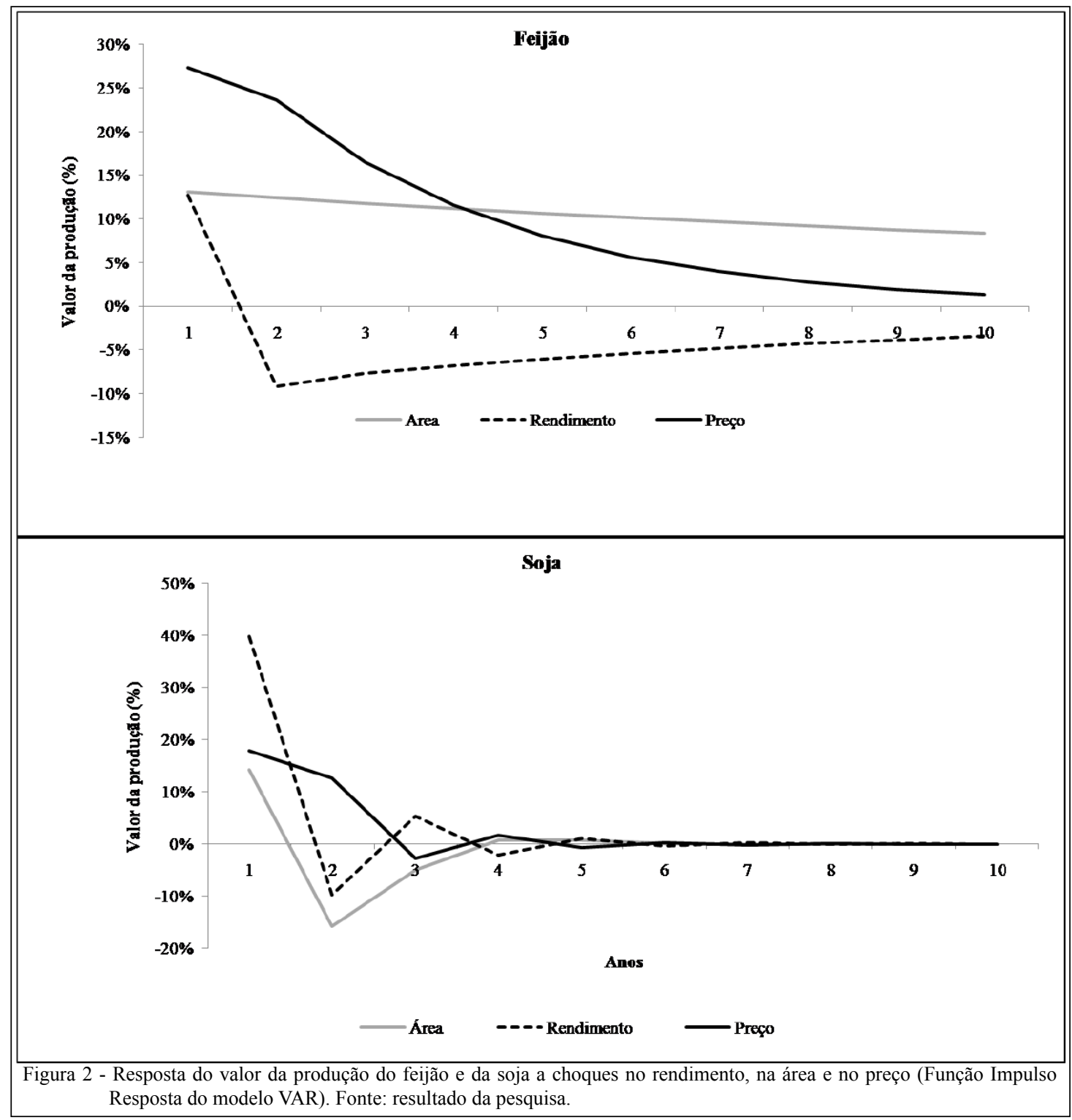

No caso do feijão, certamente políticas de restrição de importação também contribuiriam, dado o peso do componente preço no valor da produção gaúcha. No caso da soja, uma opção seria desestimular a exportação da commodity primária e estimular a agregação de valor através do processamento, o que pode elevar o VP de todo o complexo e, consequentemente, também no elo de produção, por meio da valorização do grão.

$\mathrm{O}$ valor da produção reage a choques nos componentes preço, área e rendimento de forma defasada. No caso da soja, há interações entre os três componentes, obedecendo às premissas do modelo Teia de Aranha. Assim, entre outras interações, observa-se que preços altos num determinado ano influenciam no aumento da área do segundo ano ou que aumentos de área levam à redução dos preços. Estes e outros ajustamentos se propagam até se dissiparem em alguns anos. No caso do feijão, no entanto, os choques não se dissipam completamente, mas tendem a voltarem ao valor inicial. Nesse sentido, conclui-se que, na atividade da feijocultura, há mais rigidez de ajustamentos entre a área plantada, os preços e os rendimentos, principalmente por se tratar de uma cultura de subsistência, sendo cultivada em uma determinada área para alimentação das famílias, independentemente, dos preços.

\section{INFORME VERBAL}

A - O valor da participação do agronegócio no PIB Gaúcho é controverso. Alguns autores afirmam que é de cerca de $30 \%$ 
(PORSSE, 2003), enquanto que outros colocam cifras de até 50\% (GUILHOTO et al., 2005).

B - Ver ERDAL \& ESENGUN, 2009.

$\mathrm{C}$ - As taxas de crescimento apresentadas neste artigo referem-se às taxas geométricas médias de crescimento.

D - Luiz Marçal Arrial - especialista em comercialização de feijão. Rua Taquari, 93 Centro - Sobradinho - RS; arrialmarcal@gmail.com.

\section{REFERÊNCIAS}

ALVARES, R.C. et al. Interação genótipos por ambientes em ensaios de feijoeiro-comum para agricultura familiar em Goiás In: CONGRESSO BRASILEIRO MELHORAMENTO DE PLANTAS, 6.,2011,UFRGS. Anais... PortoAlegre: Sober, 2011.3p

ARAUJO, A.C.; CAMPOS, R.T. Análise da evolução do valor da produção de cacau no estado da Bahia. In: (SOBER) O Agronegócio Brasileiro: Desafios e Perspectivas. Publicação da Sociedade Brasileira de Economia e Sociologia Rural. Brasília, SUPREMA, 1998. 1029-1039

BERLATO, M.A.; CORDEIRO, A.P.A. Variabilidade climática e agricultura do Rio Grande do Sul. In: FEDERAÇÃO DOS CLUBES DE INTEGRAÇÃO E TROCA DE EXPERIÊNCIA (FEDERACITE). (Org.). As estiagens e perdas na agricultura fenômeno natural ou imprevidência? Porto Alegre: Ideograf Editora Gráfica, 2005. p.43-59.

BUENO, R.L.S. Econometria de séries temporais. São Paulo: CENGAGE,2008. 360 p.

CARVALHO, K.L.A. et al. Efeito da área e da produtividade na produção de celulose no Brasil. Rev. Árvore, v.36, n.6, p.11191128, 2012. Disponível em: <http://www.scielo.br/scielo php? pid $=$ S0100-67622012000600012\&script $=$ sci arttext $>$. Acesso em: 20 jan doi: 10.1590/S0100-67622012000600012

CHRISTOFOLETTI, M.A.M; SILVA, R.M. da. Cointegração e causalidade no mercado de soja: análises para Brasil, China e EUA. In: CONFERÊNCIAEMGESTÃODERISCOECOMERCIALIZAÇÃO DE COMMODITIES, 2011. BM\&FBOVESPA. Anais... São Paulo: Instituto Educacional , 2011. 24 p.

ERDAL, H. et al. An analysis of production and price relationship for potato in Turkey: a distributed lag model application. Bulgarian Journal of Agricultural Science, v.15. n.3,p.243-250
2009. Disponível em: <http://www.agrojournal.org/15/03-09-09. pdf>. Acesso em: set. 2012.

FAO. 2014. Disponível em: <http://faostat.fao.org/site/291/default. aspx $>$. Acesso em: jul.2014.

FOCHEZATTO, A.; GHINIS, C.P. Fatores de crescimento e mudanças estruturais na economia do Rio Grande do Sul, 1998-2003. Ensaios FEE, v.30, n.esp., p. 427-449. 2009. Disponível em: $<$ http://revistas.fee.tche.br/ index.php/ensaios/article/view/2302/2678>. Acesso em: 20 jan.

GUILHOTO, J,M.M.et al. O PIB do agronegócio familiar no Rio Grande do Sul. In: CONGRESSO DA SOBER, 43.,2005, FEA. Anais... Ribeirão Preto: Sober, 2005. 20p.

GUJARATI, D.N. Econometria básica. 3.ed. São Paulo: McGrawHill, 2000. 496p.

IBGE. Produção agrícolas municipal. Disponível em: $<$ http://www.sidra.ibge.gov.br/bda/acervo/acervo 9. asp? $=\mathrm{c} \& \mathrm{p}=\mathrm{PA} \& \mathrm{z}=\mathrm{t} \& \mathrm{o}=11>$. Acesso em: jul.2014

IPEA. Disponível em: < http://www.ipeadata.gov.br/>. Acesso em: mar.2012.

PORSSE, A.V. Notas metodológicas sobre o dimensionamento do PIB do agronegócio do Rio Grande do Sul. Porto: FEE, 2003. (Documentos FEE, n.55).

SCALCO, P.R. et al. Choques na taxa de câmbio real e o saldo da balança comercial agropecuária brasileira: evidências da Curva J entre 1994 e 2007. Revista de Economia de Sociologia Rural, v.50,n.4, p. 595-640, 2012. Disponível em: <http://www.scielo.br/ scielo.php?pid $=$ S0103-20032012000400001\&script $=$ sci arttext $>$. Acesso em: 20 jan. doi: 10.1590/S0103-20032012000400001.

SOARES, N.S. et al.Influência da taxa de câmbio e do dólar sobre os preços da borracha natural brasileira. Revista Árvore, v.37, n.2, p.339-346, 2013. Disponível em: <http://www.scielo.br/ scielo.php?pid=S0100-67622013000200015\&script=sci_arttext $>$. Acesso em: 20 jan doi: 10.1590/S0100-67622013000200015.

SOUZA, R.S.de; VIANA. J.G.A. Tendência histórica de preços pagos ao produtor na agricultura de grãos do Rio Grande do Sul, Brasil. Ciência Rural, v.37, n.4. p.1511-1511 , 2007. Disponível em: $<$ http://www.scielo.br/scielo.php?script=sci_ arttext\&pid=S0103-84782006000500026\&lng=pt\&nrm $=$ iso $>$. Acesso em: 20 jan doi: 10.1590/S0103-84782006000500026. 